\title{
Práticas docentes criativas e histórias de formação: um estudo de caso
}

\author{
Débora Pereira Oliveira \\ Universidade Federal de São João del Rei - MG \\ Dener Luiz da Silva \\ Universidade Federal de São João del Rei - MG \\ Rita Laura Avelino Cavalcante \\ Universidade Federal de São João del Rei - MG
}

\begin{abstract}
Resumo
O presente estudo investiga o desenvolvimento criativo de uma professora cujas práticas foram consideradas estimuladoras da criatividade, segundo indicação de pares e alunos de uma escola pública de São João del Rei - MG. A pesquisa, caracterizada como um estudo de caso, reúne reflexões sobre elementos identificados na atividade docente do sujeito e sua relação com experiências de formação pessoal, educacional e profissional no tocante a barreiras ao desenvolvimento criativo e a fatores que facilitam esse desenvolvimento. Entrevistas semiestruturadas e a aplicação do teste Pensando Criativamente com Figuras (Wechsler, 2004) revelaram traços criativos que encontram origem em arranjos particulares nos quais experiências tanto favoráveis quanto inibidoras do desenvolvimento da criatividade contribuíram para a construção de uma prática estimuladora, no caso do presente estudo. Os resultados apontam a pertinência de uma discussão acerca da inclusão de elementos da criatividade e subjetividade nos cursos de formação, com o propósito de estimular a motivação do aluno para a aprendizagem.
\end{abstract}

Palavras-chave: desenvolvimento; criatividade; formação de professores.

\section{Creative teaching practices and stories of teacher education: a case study}

\begin{abstract}
This study investigates the development of a creative teacher, whose practices were considered stimulating and creative according to the indication of coworkers and students from a public school in São João del Rei / MG. The research, featured as a case study brings together reflections on elements identified in the teaching activity of the subject and its relationship to personal training, educational and professional experience regarding barriers and facilitators to creative development. Semi structured interviews and application of Pensando Criativamente com Figuras (Wechsler, 2004) revealed inventive features which are particular arrangements of origin, in which both, favorable and inhibiting experiments towards the development of creativity contributed to the construction of a stimulating practice, in this subject case. The results show the relevance of a discussion about the inclusion of elements of creativity and subjectivity in training courses, with the purpose of stimulating and motivating student to learn.
\end{abstract}

Keywords: Development; Creativity; Teacher Education.

\section{Prácticas docentes creativas e historias de formación: un estudio de caso}

\section{Resumen}

El presente estudio investiga el desarrollo creativo de una profesora cuyas prácticas fueron consideradas estimuladoras de la creatividad, según indicación de parejas y alumnos de una escuela pública de São João del Rei/MG. La investigación, caracterizada como un estudio de caso, reúne reflexiones sobre elementos identificados en la actividad docente del sujeto y su relación con experiencias de formación personal, educacional y profesional en lo tocante a obstáculos al desarrollo creativo y a factores que facilitan ese desarrollo. Entrevistas semiestructuradas y la aplicación del test Pensando Creativamente con Figuras (Wechsler, 2004) revelaron rasgos creativos que encuentran origen en arreglos particulares en los cuales experiencias tanto favorables cuanto inhibidoras del desarrollo de la creatividad contribuyeron para la construcción de una práctica estimuladora, en el caso del presente estudio. Los resultados apuntan la pertinencia de una discusión acerca de la inclusión de elementos de la creatividad y subjetividad en los cursos de formación, como propósito de estimular la motivación del alumno para el aprendizaje.

Palabras-clave: Desarrollo; creatividad; formación de profesores. 


\section{Introdução}

Ao longo de séculos o fenômeno criativo esteve permeado por concepções místicas, inatistas ou associadas à loucura, que privilegiaram o sujeito em detrimento do processo estudado. Somente na atualidade, com o amadurecimento do campo de conhecimento sobre o assunto, a criatividade passou a ser assumida como um atributo inerente ao homem e manifestada pela interação de um conjunto de fatores que tornam este objeto um complexo multidimensional (Lubart, 2007; Wechsler, 1993).

Elementos afetivos, cognitivos, motivacionais, culturais, personológicos e ambientais interferem na criatividade, o que ora dificulta um entendimento mais abrangente sobre a temática, ora revela possibilidades interpretativas variadas, conduzindo ao reconhecimento de diferentes "perfis" e traduzindo a diversidade humana ao conceber os diversos modos de adaptação (Isaksen, Puccio, \& Treffinger, 1993; Lubart, 2007; Mitjánz Martínez, 1997; Wechsler, 1993, 1998).

Estudos sobre o assunto têm buscado compreender como favorecer a manifestação criativa, aprofundando-se em linhas de pesquisa específicas sobre os aspectos enunciados, sem negligenciar a influência de variáveis concorrentes (Lubart, 2007). No presente estudo, o acesso a algumas dessas vertentes despertou o interesse pelas influências do ambiente escolar, sobretudo pelo papel do professor no desenvolvimento criativo de seus alunos.

Sendo a escolarização um dos principais meios de socialização das sociedades ocidentais, cabe ao professor parcela de responsabilidade quanto ao incentivo ou bloqueio à manifestação criativa de sua turma (Torrance, 1987). A preponderância desse profissional no gerenciamento do talento criativo é apontada por Alencar e Oliveira (2007) em consideração aos estados latentes de criatividade que ganham expressão com o estímulo adequado. Isto vai ao encontro dos achados de Torrance (1987), que detectou influências importantes da estimulação criativa docente sobre comportamentos criativos inibidos.

Não obstante, no tocante ao processo formativo do professor, a literatura aponta bloqueios no contexto escolar e nos cursos de formação para a docência que, em geral, contribuem para que este agente chegue à sala de aula despreparado para uma prática criativa e emancipatória (Ribeiro, \& Fleith, 2007).

Tais empecilhos reportam, principalmente, a valores difundidos pelo modelo econômico e social capitalista ocidental, que enfatizam a objetividade, a utilidade e a lógica, em detrimento da atividade imaginativa e da diversidade, as quais, segundo Alencar $(1999,2008)$ e Cheng, Hull e Kim (2010), revelam quão aceitáveis são as características criativas em um contexto, e por isso, para uma parcela de sujeitos cujo ajustamento a esta realidade inibe o florescimento de seus talentos, a criatividade pode encontrar uma barreira.

Além dos fatores econômicos e sociais supracitados, é válido mencionar os desafios permanentes vivenciados pela classe docente, provocados pela limitação de recursos materiais em instituições escolares, pela baixa remuneração - que obriga o professor a assumir empregos secundários e reduz seu tempo de dedicação às atividades assumidas - e pela heterogeneidade e pelo excesso de alunos em sala de aula, entre outras causas (Wechsler, 1993).

São, enfim, muitos os apontamentos da literatura que exploram as barreiras ao processo criativo. Por outro lado, como este fenômeno é complexo, multideterminado (Wechsler, 1993) e subjetivo (Barreto, \& Mitjánz Martínez, 2007), o cenário descrito é presenciado também por professores estimuladores da criatividade. Para estes as barreiras não foram significadas como tal, ou experiências paralelas propiciaram-Ihes uma formação criativa, ou sua personalidade aportou tal desenvolvimento, ou ainda, a convivência com professores como eles, estimuladores, inspiraram uma adaptação original à realidade. Aqui caberia uma gama de razões para este fenômeno, mas a curiosidade de entendê-las não se esgota neste trabalho.

Atento às diversas possibilidades, o presente estudo empreendeu uma procura por professores estimuladores da criatividade em uma escola pública de São João del Rei MG, chegando ao estudo de caso de uma professora com práticas consideradas criativas. Conduziram ao encontro deste sujeito a abordagem de pares, aos quais se solicitou a indicação do perfil descrito, e de alunos, por meio da aplicação de um questionário e da realização de um grupo de discussão.

O objeto principal, qual seja, a identificação das barreiras e dos fatores facilitadores da criatividade vividos pelo sujeito em sua trajetória pessoal, formativa e profissional, foi investigado pela aplicação, no sujeito, de entrevistas semiestruturadas e do teste Pensando Criativamente com Figuras (Wechsler, 2004), instrumentos escolhidos para subsidiar o entendimento de como esses elementos se correlacionaram e qual a importância de cada fator no resultado final.

A seguir, são aprofundadas as estratégias de seleção e o caso investigado - este dividido em seis tópicos que buscaram explorar: a história da professora, elementos criativos identificados em sua prática, características criativas, a criatividade de seu produto, além de bloqueios e facilitadores encontrados em sua trajetória. Com base nesses achados, a última parte trata as informações colhidas com a elaboração de questionamentos para o fomento de estudos posteriores.

\section{Método}

\subsection{Seleção de sujeitos}

O sujeito foi selecionado em uma escola pública de São João del Rei, indicada pela Superintendência Regional de Ensino da microrregião a que pertence o município. Os critérios para o recorte desta instituição respeitaram resultados objetivos alcançados em avaliações externas e destaques obtidos, como premiações locais e no âmbito nacional. 
Decidiu-se fazer uma seleção com base em indicações de pares e alunos. O primeiro passo foi delimitar um nível de ensino, de modo a cuidar para que os colaboradores iniciais da pesquisa falassem de experiências similares. O contato com a diretora da instituição inaugurou esta etapa, sendo-Ihe solicitado que indicasse até seis professores de classes entre o sexto e o nono anos do Ensino Fundamental cujas práticas, em sua perspectiva, fossem criativas, justificando os apontamentos. Estes docentes, por sua vez, foram consultados em um segundo momento, com a mesma solicitação, e então uma rede de indicações foi sendo estabelecida, revelando, qualitativa e quantitativamente, sujeitos que poderiam atender aos interesses deste estudo.

Para complementar tais informações, optou-se pela aplicação, aos alunos do mesmo nível de ensino, de um questionário com as seguintes questões: a) Para você, quais são as características de uma aula criativa?; b) Dos professores que você tem neste ano, qual você considera o mais criativo nas aulas?; c) Pensando no professor que você acaba de mencionar, como se sente em relação às aulas dele? Que facilidades Ihe trazem?. Ressalta-se que na segunda questão foi permitida a citação de mais de um professor, no momento de aplicação.

Percorrendo o total de 23 turmas, foram somados 115 questionários, os quais colaboraram para que um grupo de professores atraísse a atenção deste estudo. Para aprofundar os achados desta etapa e filtrar as informações colhidas, num terceiro momento foram organizados dois grupos de discussão, de acordo com o quadro de professores por turma, para acessar concepções presentes nos alunos e elementos criativos das práticas docentes descritas.

Chegou-se ao número de cinco sujeitos, dois dos quais aceitaram prontamente o convite para compartilhar sua história pessoal, educacional e profissional. Nesse momento surgiu o caso de Liz, tratado neste artigo, a qual reuniu dados de pares, alunos e de si mesma para a investigação de elementos criativos de sua prática docente e dos facilitadores e inibidores identificados ao longo de sua formação.

\subsection{Design metodológico}

A realidade apresentou Liz como um "caso" de estudo em que Stake (1983) incluiu histórias de sujeitos que constituem focos representativos de um universo mais amplo, sem que haja a possibilidade ou pretensão de uma generalização comparável. Neste sentido, elegeu-se como estratégia metodológica o estudo de caso instrumental (Stake, 1983) em que, diante de um caso típico ou representativo, busca-se o esclarecimento ou aprofundamento sobre um assunto.

Conforme Ventura (2007), isto constitui um valioso recurso para construções hipotéticas e redefinições de problemas pouco investigados, como é próprio do campo de conhecimento investigado. Yin (2010), por sua vez, releva a adequação da estratégia a pesquisas de caráter exploratório que busquem apreender aspectos holísticos da realidade. Diante disso, tem-se que a investigação aprofundada pode contribuir para a compreensão do sujeito, perpassando, inclusive, aspectos de sua formação docente.

\subsection{Instrumentos}

Neste estudo, elementos conhecidos durante a seleção foram incorporados às análises, em razão de descreverem o objeto focado. Os instrumentos lançados nesta etapa foram entrevistas semiestruturadas com a Diretora e professores por ela indicados em que foram colocadas as seguintes questões: a) "Na sua percepção, o que é uma aula criativa?"; b) "Nesta escola, quais professores a desenvolvem com turmas entre o sexto e o nono anos?"; c) "Quais os elementos das aulas destes professores e que efeitos são percebidos nos alunos?".

Para os alunos, foram aplicados questionários explorados em um grupo de discussão posterior, objetivando o aprofundamento das respostas ao roteiro apresentado anteriormente. Uma vez selecionado o sujeito, para acessar as reflexões pessoais e o significado das experiências do professor foram utilizados como ferramentas entrevistas semiestruturadas e o teste Pensando Criativamente com Figuras (Wechsler, 2004). Quatro entrevistas ocorreram em local à escolha do sujeito e em tempo variável (em média de uma hora), explorando um roteiro direcionado a histórias de infância e de escolarização, relacionamento com pais e pessoas marcantes, interesses próprios e seu desenvolvimento, traços, experiências escolares e pessoais que foram motivadoras ou desestimulantes, acompanhamento escolar, escolha profissional, histórias da graduação e da prática. Os diálogos foram gravados e posteriormente transcritos para análise. O teste utilizado - cuja versão original, a de Paul Torrance, é uma das mais utilizadas mundialmente -, foi validado pela professora Solange Wechsler (2004) para a realidade brasileira e reúne um conjunto de estímulos incompletos que devem ser continuados em desenhos para os quais o sujeito tenha dado títulos, conforme a instrução. Tais desenhos foram pontuados de acordo com a identificação - ou não - dos seguintes elementos: fluência, flexibilidade, elaboração e originalidade (aspectos cognitivos); expressão da emoção, fantasia, movimento, perspectiva incomum, perspectiva interna, uso de contextos, combinação, extensão de limites e títulos expressivos (aspectos afetivos) (Wechsler, 2004). O instrumento foi aplicado em Liz após sua seleção para a pesquisa e sua participação em entrevistas, como recurso para complementar informações coletadas em etapas anteriores.

\section{Resultados}

Para sistematizar os dados colhidos, as categorias seguintes seguem o entendimento dos elementos criativos identificados nos discursos sobre a prática de Liz e sua constituição histórica em relação aos facilitadores e inibidores identificados por ela. 
a) Dados coletados na etapa de seleção. A etapa de seleção gerou um conjunto de informações relevantes, que, segundo as concepções assumidas pelos colaboradores, fundamentam o caso em estudo. Pares que indicaram a professora Liz como criativa consideraram sua capacidade para a elaboração de aulas diferenciadas, definidas como oportunidades em que há exploração de outros espaços, aplicação de atividades práticas e de metodologias alternativas em relação ao uso do quadro-negro e da explicação oral. Entre os entrevistados, uma colega justifica sua indicação pelo interesse despertado nos alunos, concebendo a aula criativa como aquela que atrai motivação e participação. Outro par baseia a escolha em sua percepção sobre os posicionamentos de Liz em reuniões, quando a professora demonstra envolvimento com a prática e sensibilidade na relação com o aluno. O sujeito não foi referenciado pela Diretora, mas recebeu indicação de quatro dos seis pares abordados. Entre os alunos, atraiu 19 indicações do total de 30 respondentes que pertenciam a turmas para as quais Liz lecionava naquele ano. $\mathrm{Na}$ análise dos questionários encontrou-se que os colaboradores, em sua maioria, explicaram a menção a Liz pela prática de aulas diferenciadas no tocante às atividades e aos espaços explorados. Quase todos destacaram qualidades de respeito, sensibilidade e abertura como características de Liz que contribuíam para a criatividade de suas aulas, parecendo estar o ensino criativo vinculado a traços do professor, na concepção destes respondentes. No grupo de discussão, tais informações foram corroboradas e exemplificadas com a colocação de que uma postura aberta e respeitosa do professor somada a métodos originais de ensino, elementos que no caso Liz compõem uma aula criativa, que por sua vez, favorece a aprendizagem.

b) Apresentação. Primogênita de um casal de sitiantes, Liz separou-se muito cedo da família para iniciar sua vida escolar, aos seis anos, quando passou a morar com um casal de tios na pequena cidade próxima. Segundo ela, as obrigações da vida adulta chegaram-lhe cedo. A menina convivia com poucas crianças de sua idade, basicamente no horário das aulas, e assumiu, muito nova, responsabilidades domésticas. Nas brincadeiras solitárias ouvia de seu tio: "Trate de estudar". Diz ter sido uma criança tímida, cheia de medos e também muito responsável. Quando, aos catorze anos, sofreu o desajuste da morte da mãe, com quem tinha forte laço, assumiu preocupações com o estudo dos irmãos, estando a caçula com apenas dois anos. Assim, iniciou a vida profissional prematuramente, chegando ao Ensino Superior por influência de amigos da família. O pai, novamente casado, esteve ausente nesta fase de Liz. As dificuldades enfrentadas por ela nesse período foram grandes, especialmente as ligadas à falta de recursos financeiros. Liz trabalhava durante o dia e deslocava-se para a faculdade à noite, à mercê de caronas. Iniciou sua carreira como professora pouco antes de se formar e em outra área de conhecimento (Educação Física). Poucos anos depois iria concluir o curso de Ciências Biológicas, carreira na qual atua há 20 anos. c) Elementos criativos da prática de Liz. Quanto às colocações de pares e alunos, é possível identificar a percepção de que uma aula criativa desperta o interesse do aluno, tal como encontrou Wechsler (2001), e Liz tinha capacidade para isto. Traços de abertura, manifestados na criação de um clima favorável ao diálogo e ao questionamento, associam-se a um nível de exigência conhecido pelos alunos e encontram reflexo na história de Liz, em que os sujeitos mais marcantes de seu desenvolvimento apresentaram perfis semelhantes, conforme sua percepção. A mãe, a professora do primário e a professora de História no Ensino Médio, mulheres afetivas e exigentes, foram exemplos de pessoas que despertaram em Liz o interesse e prazer pelo estudo, visto por Wechsler (2001) como um dos efeitos de um ensino criativo. A autora, em trabalho anterior (1993), remete ao conceito de "mentor" como aquele capaz de criar vínculos afetivos e de confiança com o sujeito, podendo colaborar para um destino criativo, posição semelhante à desses sujeitos na vida de Liz. Desvendar necessidades dos alunos parece um desafio permanentemente assumido pela professora. Neste sentido, invoca interpretações de experiências pessoais, reações intuitivas e conhecimentos técnicos.

Liz capta intuitivamente as lacunas de sua formação e busca preenchê-las na formação de sua classe, oferecendo as condições das quais sentira necessidade em sua própria formação. Isto demonstra o dom de intuição, que Cheng e cols. (2010) apontam como um traço criativo. Quanto aos reflexos formativos sobre a prática, autoras como Alencar e Oliveira (2007) encontraram que professores criativos conheceram experiências estimuladoras em sua formação. Sem se negar que isso possa ter ocorrido na história de Liz, sua fala revela que o contrário prevaleceu na fase de escolarização e preparação para a docência. Como exemplo, vale mencionar o esforço da professora para fomentar um clima de aceitação de ideias e dúvidas, de modo que seus alunos não vivenciem a ansiedade que a acompanhou nos anos escolares em decorrência de um ambiente em que a crítica partia do professor ou dos colegas, sem que o agente socializador investisse em uma atitude acolhedora. Como aporte a esta gama de comportamentos, Liz investe em conhecimento, despendendo tempo significativo, segundo ela mesma, para a atualização de conteúdos e metodologias. Este aspecto enriquece o processo de ensino-aprendizagem e pode favorecer o desenvolvimento criativo, uma vez que o conhecimento é uma condição inaugural da criatividade (Lubart, 2007), pois oferece mais elementos para o questionamento e a elaboração de problemas, para os quais esta encontra soluções criativas.

d) Características criativas de Liz. Nas entrevistas a professora Liz revelou um conjunto de traços que, segundo a literatura específica, são altamente criativos. Alguns deles confirmaram-se na aplicação do instrumento "Pensando Criativamente com Figuras" (Wechsler, 2004), com destaque para os elementos afetivos, como se verá adiante. As indicações de pares e alunos sinalizaram o traço de abertura 
para novas experiências (Batey, \& Furnham, 2006; Batey, Furnham, \& Safiullina, 2010; Ivcevic, \& Mayer, 2007; Lubart, 2007; Mitjánz Martínez, 1997; Wechsler, 1993, 1999), entre as quais se destacam a acessibilidade para relacionamentos interpessoais e a iniciativa da professora de conduzir aulas de maneira prática e diferenciada em relação ao contexto. Em seguida, a sensibilidade da professora também foi observada (Ivcevic, \& Mayer, 2007; Mitjánz Martínez, 1997; Wechsler, 1993) no que toca à capacidade de reconhecer necessidades e motivações dos alunos e ao esforço em atendê-las - elemento presente na fala de Liz. Tal aspecto parece associado à intuição (Cheng, \& cols., 2010), que, ao possibilitar uma elaboração aprofundada das experiências da própria pessoa, desperta a percepção para as lacunas do ambiente - o que, para a professora Liz, é algo muito importante.

Marcadamente, o envolvimento com a atividade docente é uma característica de Liz, exemplificado por sua dedicação na preparação de aulas, pela reflexão sobre suas ações educativas - constantes em sua narrativa -, e pela fala carregada de emoção. Este aspecto é reconhecido como elemento criativo por autores como Torrance (1987) e Wechsler (1993). Dadas as circunstâncias de dificuldades enfrentadas por Liz, cabe elencar, ainda, a persistência diante de obstáculos, característica criativa sustentada por Ivcevic e Mayer (2007), Morais (2004) e Lubart (2007).

Identificou-se que Liz superou bloqueios socioculturais, enfrentando medos arraigados, além de condições materiais pouco favoráveis à extensão de seus projetos pessoais e profissionais. O teste "Pensando Criativamente com Figuras" (Wechsler, 2004) apontou a prevalência de traços afetivos em relação aos cognitivos, ou seja, elementos de natureza afetiva alcançaram pontuação maior que a dos elementos cognitivos. Para exemplificar, os maiores escores foram obtidos nos quesitos expressão da emoção e movimento (percentis 99).

O primeiro elemento diz respeito à tendência a uma orientação intuitiva e pautada pela sensibilidade afetiva e pela paixão por uma determinada área, características notadas no contato com Liz. O movimento, por sua vez, relaciona-se à praticidade e produtividade da professora. Por outro lado, a professora Liz apresentou limitações nos itens originalidade e extensão de limites, o que pode estar vinculado ao poder de bloqueios de ordem cultural ou pessoal à sua criatividade, os quais se traduzem em dificuldades em opor-se a padrões, valores e tradições vigentes.

e) Criatividade de Liz. A criatividade da professora Liz parece fortemente associada à necessidade, conforme conceito de Torrance, que toma a criatividade como "um processo natural motivado por uma forte necessidade humana" (Torrance, 1987, p. 190). Liz não encontrou muitos recursos, mas criou maneiras originais de se adaptar às adversidades que enfrentou, seja pela superação de algumas barreiras ao processo criativo, seja pela vivência da fome que enfrentou junto com os irmãos, seja ainda por ter construído uma história diferente para seus alunos, recombinando elementos de suas experiências.
As qualidades de novidade e utilidade do produto de Liz (sua aula) tornam-no criativo, se considerada a perspectiva de diversos autores, os quais reconhecem tais características como imprescindíveis à manifestação criativa (Barreto, 2007; Henessey, \& Amabile, 1988; Isaksen, \& cols., 1993; Lubart, 2007; Mitjánz Martínez, 1997). No âmbito da Psicometria, o instrumento "Pensando Criativamente com Figuras" (Wechsler, 2004) apontou os índices de criatividade figural 1 e 2, que revelaram medidas gerais para o fenômeno em Liz: o primeiro se refere à influência da cognição sobre a manifestação criativa em figuras, e o segundo refere-se conjuntamente a influências cognitivas e afetivas. Neste sentido, a professora apresentou resultados de 77 e 86, respectivamente, os quais situaram o primeiro indicador abaixo da média, enquanto o outro esteve na zona mediana, segundo escalas apresentadas no instrumento.

Elementos afetivos elevaram a nota geral da professora na segunda medida, significando que esses elementos se encontram mais desenvolvidos na manifestação criativa deste sujeito do que aspectos cognitivos. Vale lembrar que, na história de Liz, pessoas significativas inspiraram-lhe superar desafios por intermédio da afetividade da criação de vínculos de proximidade e confiança, o que leva à suposição de que o exemplo de mentores ou o tipo de relação estabelecido interfere no desenvolvimento de traços e comportamentos. Wechsler (1993) ressalta que esses agentes sustentam a capacidade de despertar no sujeito fé em um destino criativo.

Analisando-se, por fim, outras concepções aceitas para este trabalho, pode-se identificar a criatividade de Liz seguindo as distinções encontradas no estudo de Ivcevic e Mayer (2007), que a entendem como do tipo "cotidiana", ou seja, aquela que não está associada a um domínio específico de conhecimento, mas em que a originalidade é vivida no nível das relações pessoais e do estilo de vida. Tal análise apoia-se também na prevalência de traços emocionais, considerando a aptidão da manifestação criativa no campo dos relacionamentos.

f) Bloqueios à criatividade de Liz. Com base nas entrevistas com Liz, percebeu-se que a professora experienciou a cultura do medo no contexto escolar, tendo assumido para si, desde então, o "medo de fracassar", "o medo de errar" e "o medo de falar em público", lembrando os bloqueios mencionados por Alencar (1989). Este clima "negativo" fortalecia-se pela ação repressora de professores e de alunos, destacando-se a crítica da professora também àqueles mestres que não repreendiam diretamente a turma, mas mantinham-se indiferentes quando os alunos mostravam atitudes desrespeitosas. No âmbito familiar, viveu experiências semelhantes junto aos tios e ao pai. Este, durante o ano em que se tornou viúvo, retirou a filha da escola para auxiliá-lo no sítio realizando as tarefas domésticas, situação que foi superada somente após cerca de um ano, quando Liz assumiu a atitude inconformada de viver na casa dos avós. Nos anos de graduação, a limitação financeira concorreu para que ela pensasse em deixar os estudos, para os quais 
não Ihe restava tempo, por conta do cansaço que o trabalho como doméstica lhe causava ao fim do dia.

Quando do contato com a profissão docente, no final de seu curso, encontrou um grande obstáculo. Segundo seu relato, o curso não a preparara para a prática, e estava ela diante da desconfiança da diretora quanto a seu trabalho, manifestada durante uma entrevista intimidadora, na qual Liz manteve seu propósito, embora estivesse insegura. Conforme lembra Wechsler (1993), a descrença do professor quanto ao potencial criativo dos alunos pode levá-los, em algum momento de sua história, a desacreditarem também de sua capacidade. As barreiras ou obstáculos enfrentados por Liz parecem encontrar relações com aspectos socioculturais, sem desconsiderar que possa também haver bloqueios pessoais, mantidas as relações com limitações da primeira ordem (Alencar, 1999, 2010).

Além desses elementos, foi possível identificar dificuldades no momento de preparação para a docência, em que ainda não havia tido contato com a prática e com as discussões sobre as adversidades de uma sala de aula. $\mathrm{Na}$ carreira profissional, a professora cita uma série de fatores que dificultavam seu trabalho, entre os quais se destacam a baixa remuneração - situação que não lhe permite dedicação exclusiva a uma escola -, e o sistema educacional, com a proibição da repetência, o que mina, segundo ela, a motivação e o desafio do aluno para a aprendizagem. A avaliação da produtividade do professor e da escola pelos órgãos competentes também é identificada por Liz como uma barreira a superar. Assim, a professora busca equilibrar-se neste contexto de tantos desníveis lançando mão da capacidade criativa para adaptação ao meio.

g) Facilitadores à criatividade de Liz. Conforme lembra Mitjánz Martínez (1997), bloqueios à criatividade constituem experiências particulares para cada sujeito, não sendo aceita na literatura a definição de um perfil único criativo. Algumas das barreiras identificadas no item acima podem ter sido, hipoteticamente, facilitadoras à criatividade, se para o sujeito Liz o desafio encarado foi seu maior motivador. Não parece possível prever, por esta razão, se uma história diferenciada produziria resultados criativos, tais quais os identificados. Neste caso, a presença de mentores (Wechsler, 1993), como citado anteriormente, mostrou-se um facilitador, quando não apenas trouxe referências, mas ofereceu condições favoráveis e acolhedoras às necessidades específicas de Liz. Além da mãe e das professoras citadas, amigos da família vieram a assumir este papel na adolescência de Liz, inspirando-a a tomar uma atitude original e adaptada em relação ao seu contexto, onde não era comum para uma jovem, pobre e mulher, a formação prolongada até o Ensino Superior.

Aspectos da personalidade da professora apareceram também em sua história como facilitadores, porém, não ficou claro, nesta reflexão posterior, se foram desenvolvidos no próprio enfrentamento de barreiras ou se motivaram a atitude corajosa desde o princípio. O que se verificou neste estudo de caso foi um interjogo entre disposições do sujeito e determinações do ambiente, sendo o fenômeno criativo multidimensional (Lubart, 2007). No caso de Liz, a afetividade aparece muito imbricada em suas relações pessoais, um dos fatores preponderantes na sua indicação por alunos, denotando a necessidade de estudos que abordem a proximidade deste tema com o desenvolvimento criativo.

Por fim, observou-se que a capacidade elaborativa, no nível das ideias, permitiu a Liz não se subverter às situações com as quais sentia-se desfavorecida, mas construir a elas significados coerentes o bastante para alcançar equilíbrio e prosseguir transformando suas experiências.

Por fim, observou-se que a capacidade elaborativa, no nível das ideias, permitiu a Liz não se submeter às situações com as quais sentia-se desfavorecida, mas construir-lhes significados coerentes o bastante para alcançar equilíbrio e prosseguir transformando suas experiências. Em decorrência deste mesmo poder intuitivo, tomado como facilitador, notou-se alta criatividade ligada às relações pessoais, dentro do conceito de Ivcevic e Mayer (2007), descrito anteriormente.

\section{Algumas considerações}

Considerando os limites deste estudo, que tomou uma unidade específica para a investigação de um fenômeno complexo e multidimensional, chegou-se a um conjunto de reflexões que busca subsidiar discussões futuras sobre o tema, inserindo observações particulares do caso apresentado.

Em consonância com o que aponta a literatura, Liz descreveu uma experiência de formação na qual recebeu pouco aporte para o exercício da docência, estando o foco de seu curso direcionado para conhecimentos específicos do campo das Ciências Biológicas. Apesar disso, a professora desenvolveu uma prática diferenciada em relação às lacunas de sua formação, como sugere a indicação feita por pares e alunos e sua própria narrativa.

A este ponto associa-se a reflexão sobre duas condições. Em primeiro lugar, chama a atenção a busca permanente de Liz. Tal movimento mostrou-se presente em sua trajetória pessoal e profissional em busca de soluções para a sobrevivência da família ou para a fomentação de aulas estimuladoras, que visam motivar os alunos e, em consequência, motivar-se a si mesma. Liz lançou mão de dispositivos que parecem não ter sido estimulados em sua formação, mas encontraram origem em arranjos de experiências particulares. Assim, diante de um professor que estimule a criatividade e que possa não ter sido estimulado em sua trajetória de formação, emerge a questão: qual, então, deve ser o papel da escola no desenvolvimento criativo?

Embora a literatura aponte algumas dessas respostas, os achados deste estudo não permitiram o encontro direto delas, mas sugere uma reflexão sobre o movimento de busca apresentado por Liz. Se ele é favorável à atitude criativa, cabe pensar que o incentivo ao questionamento e à exploração dos fatos favorece o desenvolvimento da criati- 
vidade. Assim, é possível supor que este constitui uma das bases de um ensino criativo.

A segunda condição diz respeito ao exercício de reflexão sobre a prática referido por Liz. A capacidade elaborativa e a intuição da professora parecem conduzi-la também a um questionamento sobre si e sobre seus produtos, acumulando experiências que subsidiam construções sempre mais adaptadas ao contexto e enriquecidas de elementos novos.

Nóvoa (2004) entende o "formar" e o "formar-se" como partes de um mesmo processo, sugerindo a necessidade de inserção da subjetividade no processo formativo. Schön (2000) defende a postura reflexiva deste profissional, salientando que é propriamente o "conhecer-na-ação" que provoca o aprimoramento do docente. O caso de Liz traz indicativos de que a reflexão permanente do professor sobre sua prática pode contribuir para a construção de aulas estimuladoras da criatividade, levando à suposição de que talvez o trabalho direcionado à subjetividade do professor durante sua formação influencie também seu desenvolvimento criativo.

Quanto à criatividade de Liz, o instrumento "Pensando Criativamente com Figuras" (Wechsler, 2004) demonstrou um nível mediano, com prevalência de características emocionais. Os mesmos traços foram justificados por pares e alunos durante a indicação do sujeito, parecendo haver uma percepção do professor criativo como aquele que apresenta habilidades ligadas ao relacionamento interpessoal. Igualmente, dentro dos subgrupos criativos encontrados por Ivcevic e Mayer (2007), a criatividade de Liz pode ser definida como a cotidiana, ou seja, a orientada para relações pessoais.

Neste sentido, pode-se questionar: a alta indicação de Liz deveu-se, sobretudo, a suas habilidades pessoais? Em caso afirmativo, é possível tratá-la como uma professora criativa?; ou ainda: seria o relacionamento interpessoal uma condição imprescindível para uma prática docente estimuladora da criatividade, haja vista a alta associação entre pares e alunos respondentes?

Para explorar essas questões, identifica-se a necessidade de mais estudos. Mostra-se importante conhecer, por exemplo, a associação de habilidades criativas com áreas específicas de atuação.

Outra observação deste estudo diz respeito ao fato de Liz ter demonstrado reeditar duas características de mentoras conhecidas em sua história: a afetividade e a exigência. Nesta perspectiva, verificou-se que traços de abertura apontados na indicação da professora por alunos não estiveram associados à permissividade, pois o grupo revelou que a professora exige disciplina e compromisso. Assim sendo, pode ser que o professor criativo seja aquele que estabeleça uma relação de respeito mútuo com o aprendiz.

Por fim, cabe refletir sobre a especificidade deste caso, considerando que, de um universo de cerca de 40 professores, apenas cinco mostram-se elegíveis para esta pesquisa, segundo critérios de indicação. Tal fato induz à preocupação quanto à educação de futuros professores e também de outros profissionais, uma vez que a capacidade de reinvenção e adaptabilidade desponta como uma grande necessidade para a sobrevivência.

Neste sentido, estudos que explorem possibilidades criativas de professores associadas a experiências de formação podem contribuir com o apontamento de elementos favoráveis a uma educação emancipatória, enriquecendo as reflexões sobre o processo de formação docente, para, no futuro, redefinir caminhos. Ressalta-se que, no cenário atual, marcado por conjunturas desafiadoras, parece imperioso que a educação rediscuta os modelos, estratégias e dispositivos adotados, preparando sujeitos para a solução de problemas particulares e coletivos.

\section{Referências}

Alencar, E. M. L. S. (1989). A repressão ao potencial criador. Psicologia, Ciência e Profissão, 9(3), 11-13.

Alencar, E. M. L. S. (1999). Barreiras à criatividade pessoal: Desenvolvimento de um instrumento de medida. Psicologia Escolar e Educacional, 3, 123-132.

Alencar, E. M. L. S. (2007). Criatividade no contexto educacional: três décadas de pesquisa. Psicologia: teoria e pesquisa, 23, 45-49.

Alencar, E. M. L. S. (2008). Repensando a educação para o século XXI. Recuperado: 07 abr. 2010. Disponível: http://www. fcee.sc.gov.br/index .phpoption=com_docman\&task=doc_ view\&gid=95\&ltemid $=91$.

Alencar, E. M. L. S., Bruno-Faria, M. F., \& Fleith, D. S. (2010). A medida da criatividade: possibilidades e desafios. Em E. M. L. S. Alencar, M. F. Bruno-Faria, D. S. Fleith, \& col. (Orgs.), Medidas de criatividade (pp. 11-34). Porto Alegre: Artmed.

Alencar, E. M. L. S., \& Oliveira, Z. M. F. (2007). Criatividade na formação e atuação do professor do curso de Letras. Psicologia Escolar e Educacional, 11(2), Campinas, 223-23.

Barreto, M. O. (2007). O papel da criatividade no ensino superior. Diálogos e Ciência, 5 (12), 1-13.

Barreto, M. O., \& Mitjánz Martínez, A. (2007). Possibilidades criativas de professores em cursos de pós-graduação stricto sensu. Estudos de psicologia, 24(4), 463-473.

Batey, M., \& Furnham, A. (2006). Creativity, intelligence, and personality, a critical review of the scattered literature. Genetic, Social and General Psychology Monographs, 132(4), 355-429.

Batey, M., Furnham, A., \& Safiullina, X. (2010). Intelligence, general knowledge and personality as predictors of creativity. Learning and individual differences, 20, 532- 535.

Cheng, Y., Kim, K. H., \& Hull, M. F. (2010). Comparisons of creative styles and personality types between American and Taiwanese 
college students and the relationship between creative potential and personality types. Psychology of Aesthetics, Creativity, and the Arts, 4 (2), 103-112.

Henessey, B.A., \& Amabile, T. M. (1988). The conditions of creativity. Em R. J. Sternberg (Org.), The nature of creativity (pp. 11-38). New York: Cambridge University Press.

Isaksen, S. G., Puccio, G. J., \& Treffinger, D. J (1993). An Ecological Approach to Creativity Research: Profiling for Creative Problem Solving. The Journal of Creative Behavior, 27 (3), 147-170.

Ivcevic, Z., \& Mayer, J. D. (2007). Creative types and personality. Imagination, cognition and personality, 26 (1-2), 65-86.

Lubart, T. (2007). Psicologia da criatividade. Porto Alegre: Artmed.

Mitjánz Martínez, A. (1997). Criatividade, personalidade e educação. Campinas, SP: Papirus.

Morais, M. F. (2004). A pessoa e o processo criativos: análise de testemunhos de Inventores independentes portugueses. Comunicação e Sociedade, 6, 234-255.

Nóvoa, A. (2004). Novas disposições dos professores: a escola como lugar de formação. Correio da Educação, 47, 1-4.

Ribeiro, R.A., \& Fleith, D. de S. (2007). O estímulo à criatividade em cursos de licenciatura. Paidéia, 17(38), 403-416.

Schön, D. A. (2000). Educando o profissional reflexivo, um novo design para o ensino e a aprendizagem. Porto Alegre: Artmed.
Stake, R. E. (1983) Estudo de caso em pesquisa e avaliação educacional. Educação e Seleção Fundação Carlos Chagas, 7, $5-14$

Torrance, E. P. (1976). Criatividade: Medidas, testes e avaliações (A. Arruda, Trad.). São Paulo: Ibrasa.

Torrance, E. P. (1987). Teaching for creativity. Em S. G. Isaksen (Org.), Frontiers of creativity research. Beyond the basics (pp. 189-215). Buffalo, NY: Bearly Limited.

Ventura, M. M. (2007). O Estudo de Caso como modalidade de pesquisa. Revista SOCERJ, 20(5), 383-386.

Wechsler, S.M. (1993). Criatividade: descobrindo e encorajando. Campinas: Psy.

Wechsler, S.M. (2001). Criatividade na cultura brasileira: uma década de estudos. Psicologia: Teoria, Investigação e Prática, 1, 215-226.

Wechsler, S. M. (2004). Avaliação da Criatividade por Figuras. Teste de Torrance. Versão Brasileira ( $2^{\mathrm{a} e d}$ ). Laboratório de Avaliação e Medidas Psicológicas - PUC-Campinas, Campinas: Impressão Digital do Brasil.

Yin, Robert K. (2010). Estudo de caso: planejamento e métodos. 4.ed. Porto Alegre: Bookman, $248 \mathrm{p}$.

\section{Sobre os autores}

Débora Pereira Oliveira (de.psic@hotmail.com)

Mestranda em Psicologia pela UFSJ

Dener Luiz da Silva (densilva@ufsj.edu.br)

Professor Doutor da UFSJ

Rita Laura Avelino Cavalcante (ritalaura.cavalcante@gmail.com) Professor Doutora da UFSJ

Trabalho derivado da Dissertação "Histórias de formação e desenvolvimento criativo: interfaces com a prática profissional de dois professores de uma escola pública de São João del Rei”, defendida em abril/2013 pelo Programa de Mestrado em Psicologia da Universidade Federal de São João del Rei (UFSJ). 